\title{
Collapse of the Pilcomayo River
}

\author{
J.P. Martín-Vide ${ }^{\mathrm{a}, *}$, M. Amarilla ${ }^{\mathrm{b}}$, F.J. Zárate ${ }^{\mathrm{b}}$ \\ a Technical University of Catalonia, Barcelona, c/Jordi Girona 1-3, D1, 08034 Barcelona, Spain \\ b Av. Jaime Paz Zamora E-2750, Tarija, Bolivia
}

\section{A R T I C L E I N F O}

\section{Article history:}

Received 25 July 2011

Received in revised form 4 December 2012

Accepted 6 December 2012

Available online $\mathrm{xxxx}$

\section{Keywords:}

Suspended load

Alluvial fan

Channel morphodynamics

Meandering

Log jam

Pilcomayo River

\begin{abstract}
A B S T R A C T
The Pilcomayo River flows south-eastwards from the Bolivian Andes across the Chaco Plains, setting the border between Argentina and Paraguay. It flows down along $1000 \mathrm{~km}$, in principle, to finally join the Paraguay River. It spills over the plains during the rainy season from January to March. The sediment load of the Pilcomayo is one of the largest in the world: 140 million tons per year, which is mostly wash load from the upland Andes. The mean concentration of suspended sediment is $15 \mathrm{~g} / \mathrm{l}$. The maximum recorded concentration is as high as $60 \mathrm{~g} / \mathrm{l}$. The river has built a large fan covering a surface of $210,000 \mathrm{~km}^{2}$, with many abandoned channels. Today, it is a river prone to avulsion, raising border disputes between the two lowland countries, Argentina and Paraguay. Moreover, the very special feature of Pilcomayo River is that it does not actually flow into the Paraguay River. Very far upstream of the mouth in the Paraguay the channel blocks itself with sediment and wood debris forcing water and sediment to spread across the plains. Moreover, the point of blockage has moved hundreds of kilometers upstream throughout the 20th century. Many environmental issues arise because of this collapse (channel discontinuity), not the least of them is the migration of fish. The future of the river concerns Bolivia and the two lowland countries.
\end{abstract}

(c) 2012 Elsevier B.V. All rights reserved.

\section{Introduction}

The objective of this paper is to circulate the case-study of the Pilcomayo River, a rare example of extreme fluvial discontinuity. The collapse, mentioned in the title, means the self-obstruction of the river channel, in such a way that the water keeps flowing further downstream but only as overland flow not as a channel flow. The continuity of the river channel from its sources down to its mouth is taken for granted in river morphology. Thus, it is claimed that this is a case of extreme fluvial discontinuity because the river channel at a certain point suddenly disappears. It will be disclosed that this results from a siltation in the channel under conditions of very high sediment loads, which implies that this point of collapse must move upstream. This sediment-driven collapse should be distinguished from the more common case of ephemeral, sporadic and intermittent rivers which are not able to discharge into others or into the sea because water seeps through the alluvial beds (this can be called flow-driven collapse). In contrast, in the Pilcomayo flows, reaching even thousands of $\mathrm{m}^{3} / \mathrm{s}$, are crossing every year the point of collapse where the river channel itself disappears. Therefore, water and sediment are sent from the channel out to the land around.

\footnotetext{
* Corresponding author at: Technical University of Catalonia, Barcelona, c/Jordi Girona 1-3, D1, 08034 Barcelona, Spain. Tel.: + 34934016476

E-mail addresses: vide@grahi.upc.edu (J.P. Martín-Vide), mabelym@yahoo.com (M. Amarilla), ZarateFJ@halcrow.com (F.J. Zárate).
}

The Pilcomayo River flows south-eastwards from the Andes, across the Chaco Plains, down, in principle, to the Paraguay River at Asunción (Fig. 1). ${ }^{1}$ The drainage basin covers the southern Andean ranges of Bolivia along $500 \mathrm{~km}$ of main river with an average slope of $1 \%$, whereas most of the rest of the channel sets the border between Argentina and Paraguay along $835 \mathrm{~km}$ in a very flat landscape with an average slope of $0.04 \%$. The material presented in this paper was collected during the European Union contract ASR/B7-3100/99/ 136 in which the EU assisted the three countries, Bolivia, Argentina and Paraguay, to develop an integrated plan for basin management. The collection work consisted of the review of unpublished reports dated back to 1977, some of them written for agencies of the United Nations, and in the new channel surveying campaigns and gauging work in the field for more than five years. Much of this material is local literature, mostly in Spanish, which readers are strongly invited to read on the web page www.pilcomayo.net/biblioteca. For the sake of brevity, this literature is not cited here, but only the very few international publications related to the topic. The presentation of this material will be divided here in three parts in subsequent sections: $i$ ) the basin-wide variables affecting the channel response, i.e. the flow of water and sediment; $i i)$ the channel features observed from the air and on the ground including the dynamics of the point of collapse, and iii) the human interventions in the channel and their effects.

\footnotetext{
${ }^{1}$ Site 1 is in Villamontes (Bolivia), site 2 is in Misión La Paz (Argentina) and Pozo
} Hondo (Paraguay) and site 3 is in Fortín Nuevo Pilcomayo (Argentina-Paraguay). 


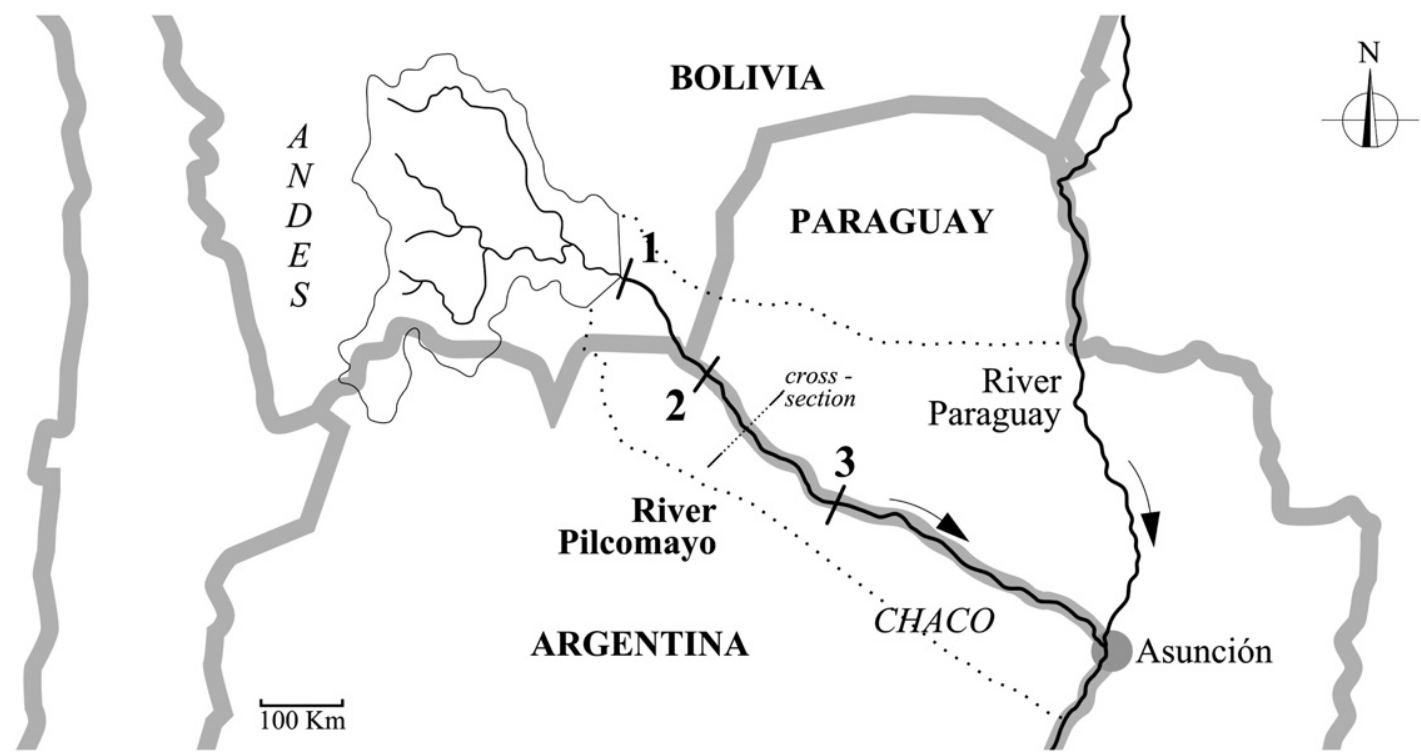

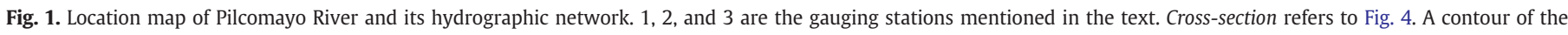
alluvial fan is drawn in dots.

From a scientific point of view, this case-study provides an opportunity to describe depositional processes in a large river system. The question to be asked is: the sediment production in the basin can be related to the channel self-obstruction and to the upstream migration of the point of collapse as a cause-and-effect process?

\section{Basin inputs: flow and sediment}

The first basin-wide input to the fluvial discontinuity of the Pilcomayo is the runoff. Data on discharges at a number of gauging stations in the three countries have been computed from daily measurements. At gauging stations 1 to 3 of the main river (Fig. 1), a cable way system allowed the placement of a propeller current-meter to measure flow velocity at several points in a number of equally spaced verticals, at least 10 verticals. Velocity records, used for discharge computation, sometimes go back more than 40 years. The methods and the length of records support the reliability of the discharge figures to be presented.

The hydrological regime of the Pilcomayo is quite predictable in its general trends. Every year a rainy season produces high discharges in the period of January, February and March. On the contrary, the dry season brings the discharge down from June to October. For the gauging station 1 (Fig. 1) located at the end of the mountainous upper part of the river, $1000 \mathrm{~km}$ upstream of Asunción, where the catchment area is $82,000 \mathrm{~km}^{2}$, the mean discharge is some $720 \mathrm{~m}^{3} / \mathrm{s}$ in February but only $35 \mathrm{~m}^{3} / \mathrm{s}$ in September (twenty times lower). Table 1 shows the monthly distribution of the runoff by averaging 31 consecutive years of data. The annual runoff varies between humid and dry years - for the data in the table the coefficient of variation is $38 \%$.
As an example, Fig. 2 is the annual hydrograph of the humid year 1984 at station 2, located $180 \mathrm{~km}$ downstream of station 1 (Fig. 1), with a catchment area of $96,000 \mathrm{~km}^{2}$. Within the 3-month rainy season from January to March, usually several peaks easily occur and exceed $1500 \mathrm{~m}^{3} / \mathrm{s}$ every year, like in the year 1984 . At gauging station 2 , the maximum recorded discharge in 30 years was $5500 \mathrm{~m}^{3} / \mathrm{s}$ and the minimum was $3.2 \mathrm{~m}^{3} / \mathrm{s}$.

Another hydrological feature is that from gauging station 1 to stations 2 and 3, further downstream in the Chaco Plains, the yearly mean discharge goes from 240 down to 225 and to $200 \mathrm{~m}^{3} / \mathrm{s}$, respectively. The river gets no tributaries along this reach, so that seepage, spilling in high flow and possibly evaporation (certainly evapotranspiration) should account for the loss in the yearly mean discharge downstream.

A second basin-wide input to the fluvial discontinuity is the sediment load. The suspended sediment was routinely sampled during daily gauging operations. Data were obtained with a USD-49 depthintegrating sampler with a $1 / 8$-inch nozzle placed with the same cable way at three verticals spaced between 20 and $40 \mathrm{~m}$. This sampling came after the work with the current-meter in stations 1 to 3. Data at station 3 covered the period 1954-1967, at station 2 1964-1975 and at station 1 since 1978. The current-meter sounded the depths too. Since 1993, the sampled material has been divided by the size $0.062 \mathrm{~mm}$, which separates silt from sand, to compute the wash load. The resulting long database of suspended sediment loads includes rainy and dry seasons as well as rising and falling limbs of the hydrographs. The bed of the lowland Pilcomayo is composed of fine grained sand with a diameter $D_{50}$ of around $0.1 \mathrm{~mm}$. The prevailing mode of transport is suspension. To support this statement, Vollmers

Table 1

\begin{tabular}{|c|c|c|c|c|c|c|c|c|c|c|c|c|c|c|}
\hline & Station & Total & Jan & Feb & Mar & Apr & May & Jun & Jul & Aug & Sep & Oct & Nov & Dec \\
\hline Runoff & 1 & 7595 & 20.2 & 24.5 & 22.7 & 9.6 & 3.7 & 2.1 & 1.7 & 1.4 & 1.2 & 1.6 & 3.7 & 7.6 \\
\hline$\left(\mathrm{m}^{3} \cdot 10^{6}\right)$ & 2 & 7095 & 19.8 & 24.4 & 22.7 & 10.9 & 3.9 & 2.3 & 1.7 & 1.3 & 0.9 & 1.3 & 3.3 & 7.5 \\
\hline Sediment load & 1 & - & 35.1 & 23.3 & 13.9 & 5.0 & 0.2 & 0.02 & 0.02 & 0.06 & 0.2 & 1.5 & 5.1 & 15.6 \\
\hline$\left(\mathrm{t} \cdot 10^{6}\right)$ & 2 & 140 & 21.7 & 39.3 & 19.3 & 5.4 & 0.8 & 0.7 & 0.1 & 0.1 & 0.1 & 0.3 & 1.7 & 10.5 \\
\hline
\end{tabular}

Up: Data of the mean annual runoff (in million of $\mathrm{m}^{3}$ ) and the mean monthly share of it (in percentage) at gauging stations 1 and 2 (see Fig. 1). Period of data is $1974-2004$.

Down: Calculation of the mean monthly percentage of the annual sediment volume (in million tons). 


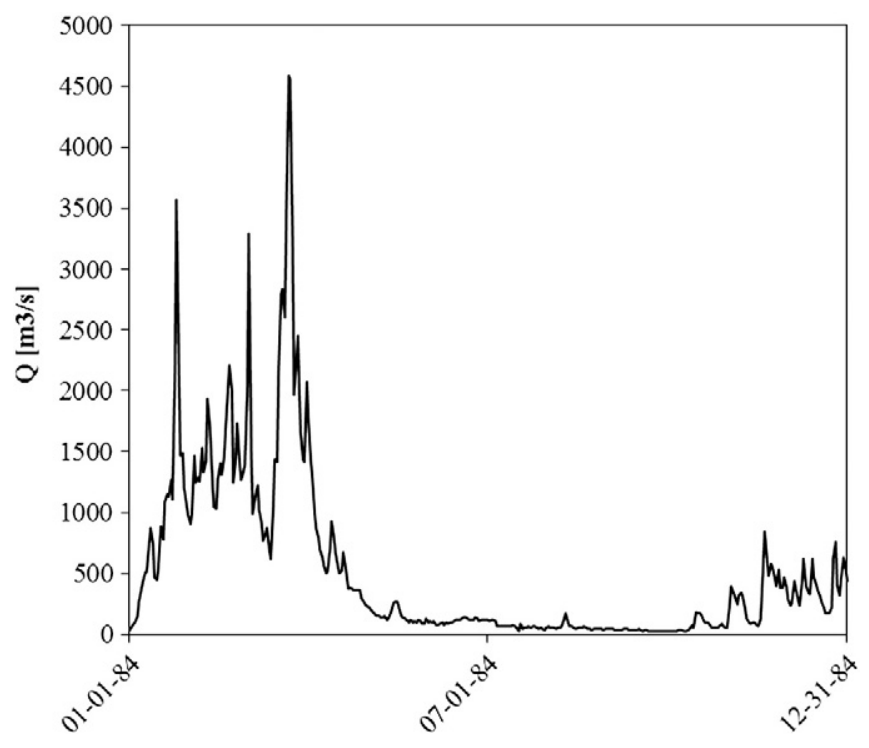

Fig. 2. Hydrograph of the year 1984 at station 2.

and Palenque (1983) found that bedload was only $12 \%$ of the total load in an Andean tributary of the Pilcomayo, where the slope was much steeper $(0.50 \%)$ but the bed grain size not much coarser, i.e. under conditions favorable to a larger bedload.

Thirty years of data at station 2, which include data not published by Guyot et al. (1990), give a mean suspended sediment load of $140 \cdot 10^{6}$ tons per year, one of the largest in the world. Some $89 \%$ of this huge amount is in the range of silt and clay, which should be considered wash load - the remaining $11 \%$ is fine grained sand. The median size $D_{50}$ of this wash load is a little larger in the dry season $(6 \mu \mathrm{m})$ than in the rainy season $(4 \mu \mathrm{m})$. The ratio of total sediment load Qs and total runoff $Q$ gives a yearly mean suspended sediment concentration Cs of $15.2 \mathrm{~g} / \mathrm{l}$ at station 1. This figure is not constant throughout the year, but non-linearity is remarkable because a concentration as low as $0.01 \mathrm{~g} / \mathrm{l}$ may occur in the dry season whereas the highest record in the rainy season reaches more than $60 \mathrm{~g} / \mathrm{l}$. The correlation between Cs and discharge Q is quite weak, anyway. For example, the daily data for one whole year at station 2 (Fig. 3) show a maximum Cs of $63.5 \mathrm{~g} / \mathrm{l}$ when $\mathrm{Q}$ was below $300 \mathrm{~m}^{3} / \mathrm{s}$, whereas for the maximum $\mathrm{Q}$, above $1500 \mathrm{~m}^{3} / \mathrm{s}$, Cs was $32 \mathrm{~g} / \mathrm{l}$, just half of its maximum. The correlation slightly improves by computing concentration for sediment particles larger and smaller than $0.062 \mathrm{~mm}$ separately, resulting fitting equations $\mathrm{Cs}=0.45 \cdot \mathrm{Q}^{0.29}$ and $\mathrm{Cs}=0.12 \cdot \mathrm{Q}^{0.82}$, respectively. Another feature of the data is that a pattern of high sediment concentrations in advance of high discharges in the rising limbs is sometimes observed (not always) when comparing the sediment and flow hydrographs.

Because of the hydrological regime of the river and the very different suspended sediment concentrations between seasons, more that $85 \%$ of the total amount of the suspended sediment is transported from December to March. Table 1 shows the computation of the monthly distribution of sediment volume, which is even more irregular than the distribution of runoff.

\section{Channel morphodynamics}

The Pilcomayo channel in the plains cuts itself through a mega alluvial fan of more than $200,000 \mathrm{~km}^{2}$ down to the Paraguay River, which is the largest of its kind on the eastern slopes of the Andes in South America. The whole of this huge area belongs to the Pilcomayo basin from an environmental point of view and yet it does not contribute to its flow, neither by tributaries nor by direct runoff. The land in the alluvial fan is very flat and sometimes the channel is perched at the fan top. Fig. 4 is one example of the few existing precise surveys across the fan, close to station 2 (see Fig. 1 for location), where one can see an abandoned channel at the fan top and the current channel at its right.

Focusing in the channel morphology moving in the flow direction, the Pilcomayo starts as a braided river issuing from its narrow valley of the last mountain range in the west, getting wider eastwards, as seen in the satellite photograph and the picture taken from the plane (Fig. 5). The pale-colored alluvial width, carved by the flow in the sand, can reach even $3000 \mathrm{~m}$. The gauging station 1 stands inside the city at the left of Fig. 5, where the channel slope is around $0.12 \%$.

Moving downstream, the channel gradually turns into a single thread meandering channel. Actually, its overall planform is meandering, with substantial in-channel bar features. Again, Fig. 6 shows photographs of the Pilcomayo from the satellite and from the plane in a region of the plains $180 \mathrm{~km}$ downstream of Fig. 5. The gauging station 2 stands inside the village at the right of the figure, where the channel slope is around $0.03 \%$, the width is $\approx 150 \mathrm{~m}$ and the depth is $\approx 3 \mathrm{~m}$. The channel is much narrower and natural cut-offs occur very often, even every year, as suggested by the oxbow lakes and how close the loop comes to being cut off in one point in Fig. 6. The extremely tortuous, uneven pattern of the meanders in Fig. 5, sometimes hairpin shaped, is unusual. An

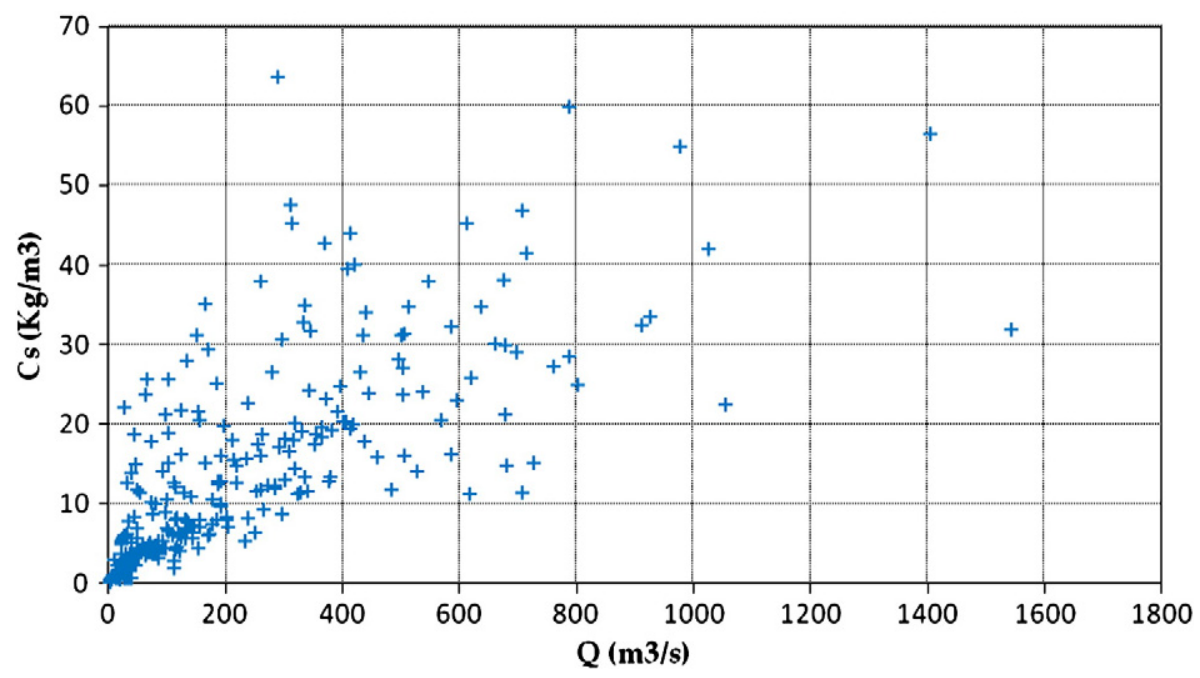

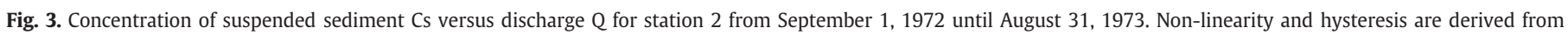
this plot. 


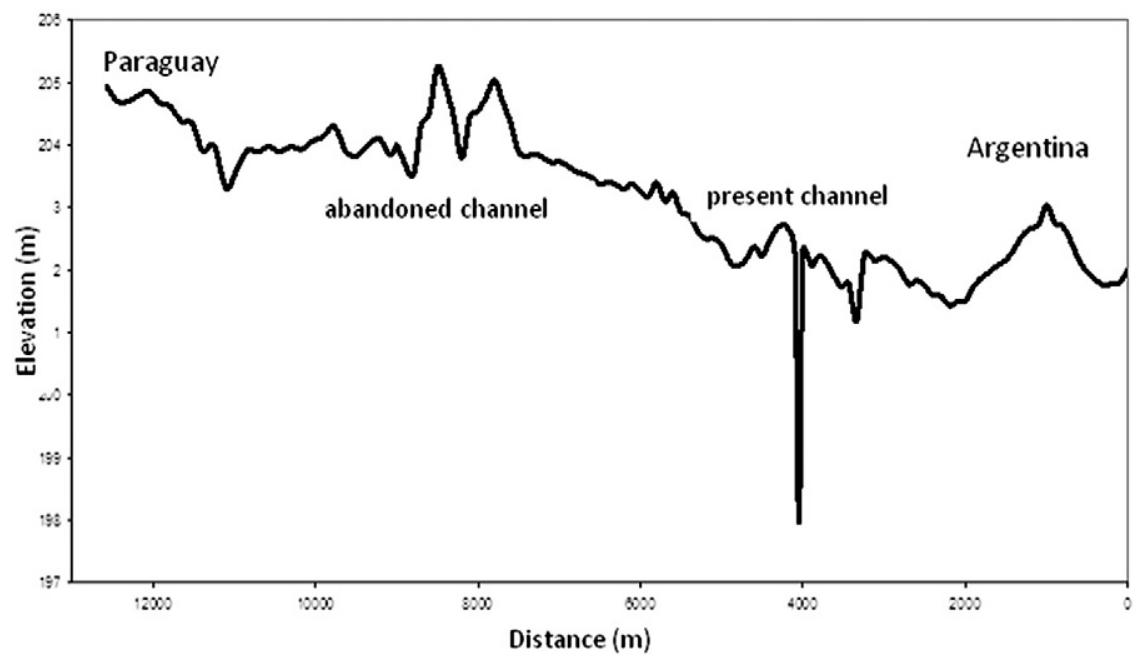

Fig. 4. Cross-section of the Pilcomayo alluvial fan and river close to gauging station 2.

example taken from the region very close to station 2 is drawn in Fig. 7, where the channel has evolved crossing towards both sides of the border, which was set by an agreement in 1945 .

Moving a little downstream, the flow is suddenly obstructed by a jam of fine sediment and log or large wood debris that completely fills the channel, which is not able to convey the water any longer. In this paper, we use collapse in the sense that the blocked river collapses at this point. Instead of channel flow, water spills over the banks in front of the jam in a tree-like pattern of small furrows (Fig. 8a). In the flood season though, the channel and the plains are fully under water and

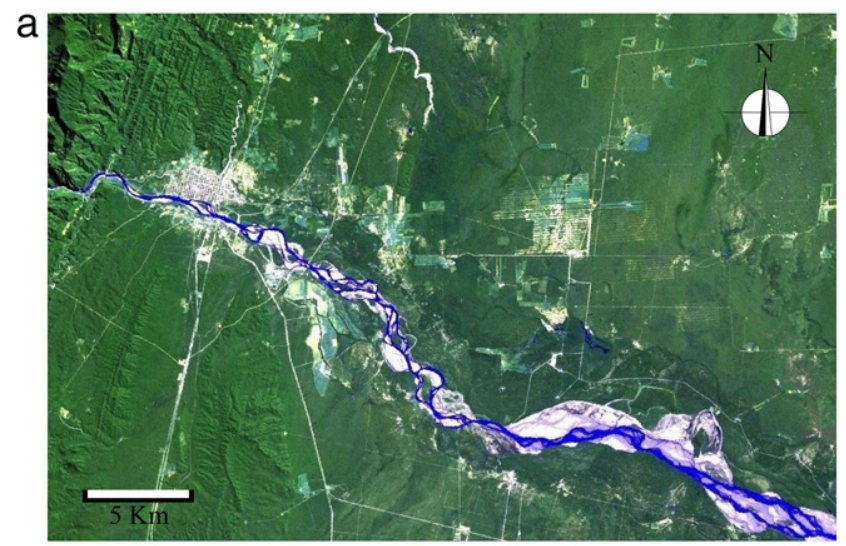

b

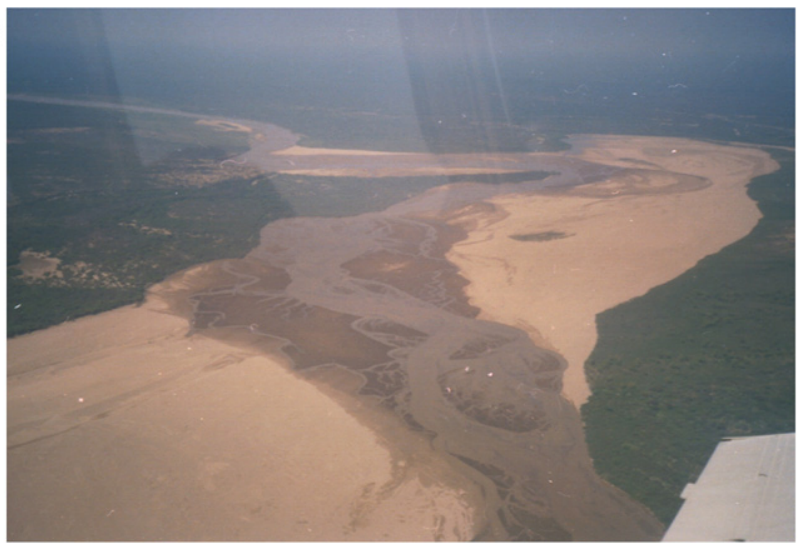

Fig. 5. Satellite and airplane photographs (flow from left to right and from foreground to background respectively) at the beginning of the lowland river. (For interpretation of the references to color in this figure legend, the reader is referred to the web version of this article.) the flow is properly overland (Fig. 8b). In any case, this spilling and spreading across the plains feeds a large marsh area in the Chaco, a very complex system of seasonal lakes, swamps and slow channels, combining surface and groundwater flow, extending eastwards and finally draining clear water with no sediment into the Paraguay (Orfeo, 1999), which is not the topic of this paper. From the ground, the jam appears as in Fig. 9a - the comparison with a beaver's dam used in several reports is telling, in the sense that the tree trunks provide a framework
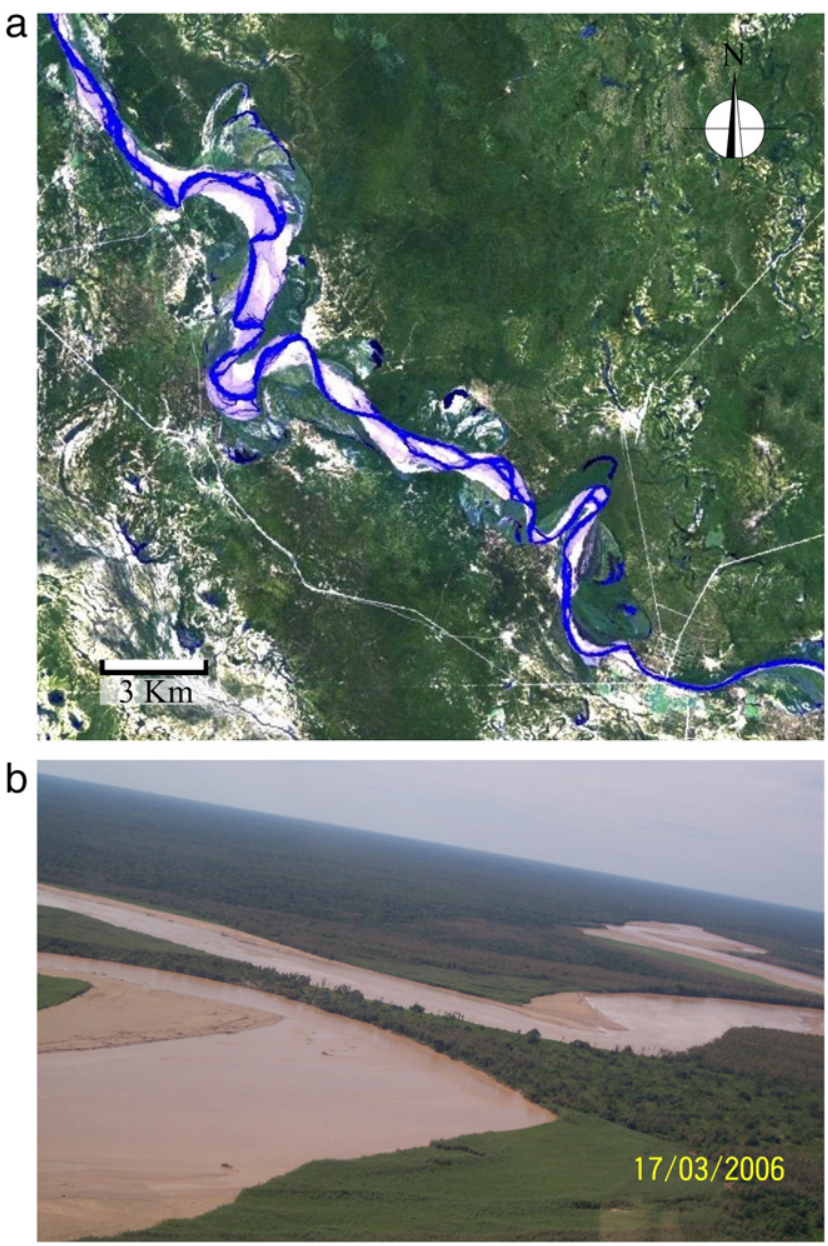

Fig. 6. Satellite and airplane photographs 180 km downstream of Fig. 2 (flow idem to Fig. 5). 


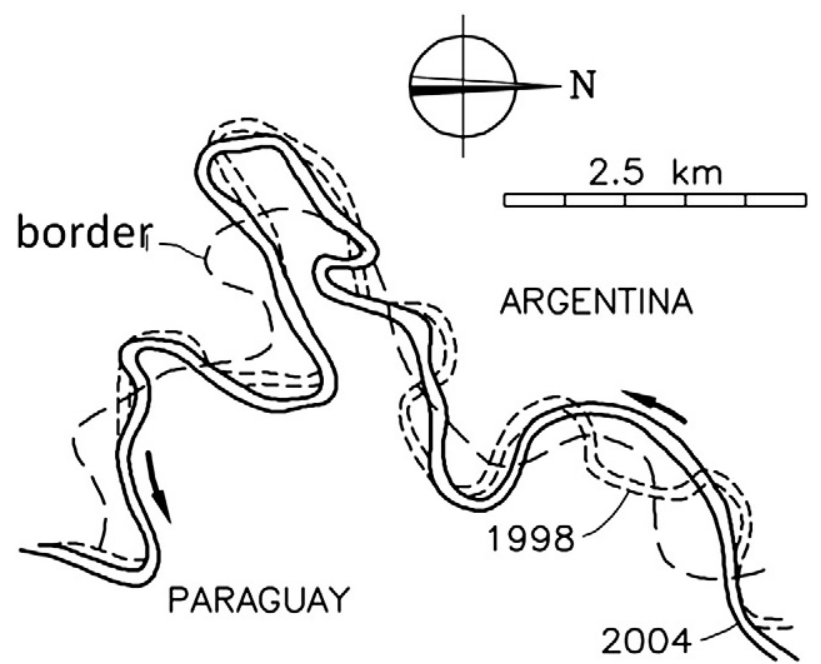

Fig. 7. River courses close to station 2 at different times. The border was set in 1945 .

which is filled with fine sand. The comparison may be misleading though because the jam at a particular stage is just the upstream-most tip of a channel clogged before by the same mechanism, not a single dam. Most of the wood comes from the tree Tessaria integrifolia (locally called Palo Bobo), very common in the Chaco Plains. It grows fast and spreads up to the river banks, being removed by bank erosion and colonizing the abandoned channels as well (Fig. 9b).

As a result of the spilling throughout the flood season, land rises in the floodplain around the jam at a rate of about half a meter per year. This sedimentation has been monitored with stakes and through marks on trees. It seems that a dome-like deposit is formed every flood season, extending some $15 \mathrm{~km}$ downstream of the point of collapse, $5 \mathrm{~km}$ upstream of it and $10 \mathrm{~km}$ across the plains, on both sides of the channel, in principle. These dimensions fit quite well with the volume of the annual suspended sediment load $\left(140 \cdot 10^{6} \mathrm{t}\right)$ - assuming a specific weight of $2 \mathrm{t} / \mathrm{m}^{3}$, this load is equivalent to a $1 / 2 \mathrm{~m}$-deep layer of sediment in a square with sides measuring $11.8 \mathrm{~km}$. Note that, on the contrary, $1 \mathrm{~km}$ of the $150 \mathrm{~m}$-wide, 3 m-deep channel, amounting a volume of $450,000 \mathrm{~m}^{3}$, would be able to hold less than 1 million tons or, in other words, less than $1 \%$ of the total sediment coming to the jam per year. If the current channel shares even a small part of the sedimentary burden, it has no other choice than to fill and recede. Luckily, it is able to rid itself of much of the sediment load by spilling across the plains. In conclusion, the channel must move upstream with each flood season.

So far, it has been emphasized that the collapse occurs suddenly in a point of the river path, as if a description in plan view is enough. But, together with spilling, land building and channel receding around the point of collapse, the bottom of the last kilometers of the "active" channel silts as well, so that the slope becomes milder, the channel capacity decreases and flow velocity slows down, too. The decrease in the channel capacity spans from almost $2000 \mathrm{~m}^{3} / \mathrm{s}$ in the wide braided channel upstream (Fig. 5) down to as little as $200 \mathrm{~m}^{3} / \mathrm{s}$ in the narrow tortuous channel downstream (Fig. 6). Therefore, the flow goes overbank for a progressively lesser discharge further downstream, producing some spilling of the high flows in between. Thus, the competence of the flow to maintain sediment in suspension is weakened, so that a feedback occurs for more silting of the bed and filling of the channel - not to mention the ability of the flow to cut through old deposits which is completely lost. On the contrary, the spilling contributes to the sedimentation in the plains upstream of the point of collapse.

This sedimentation around the jam is doing the contemporary geomorphic work in the building of the mega alluvial fan of the Pilcomayo River. The satellite photograph of the whole Chaco discloses a channel once longer than it is nowadays and traces of many former different river paths issuing like a fan from an apex, as well (Iriondo, 1993; Horton and DeCelles, 2001). A number of sub-fans and sub-apex can be identified. The increase in elevation because of land building makes the channel perch higher within its fan, with lower land on both sides and a milder gradient. This provides feedback for more sedimentation and, thus, a more perched channel. At the same time, the point of collapse is retreating towards its fan apex. These two factors may trigger an avulsion of the channel, i.e. a sudden shift of river path in the fan after the siltation of an old channel. Avulsion is the mechanism explaining the essential instability of rivers running over dynamic alluvial fans and the different paths in the past. This point already connects the morphodynamics of the Pilcomayo with the human concerns of the next paragraph.

\section{Human-made channels}

Argentina and Paraguay have been very concerned about the lowland Pilcomayo River throughout the 20th and 21th centuries, mostly because of water and fish. Water is essential as a supply to the population and for cattle farming in both countries. The fisheries of Sábalo (Prochilodus lineatus), both industrial and not, are a very prominent source of food and income for the population in the lowland basin of all three countries, including Bolivia. Regarding water management in such a dynamic system, every year, the hope of each country is to be favored by much spilling on its side upstream of the point of collapse and by the main direction of the overland flow around it. Regarding morphodynamics, it is not strange that events impacting the long common fluvial border between the two lowland countries (see Fig. 7) have led sometimes to disputes. The frequent meander cut-off is the least serious event actually, unlike other fluvial borders of the world, as it is argued next. Bolivia should not be cast aside from these concerns because it can control the two inputs from upland, namely flow and sediment, affecting the channel response. a

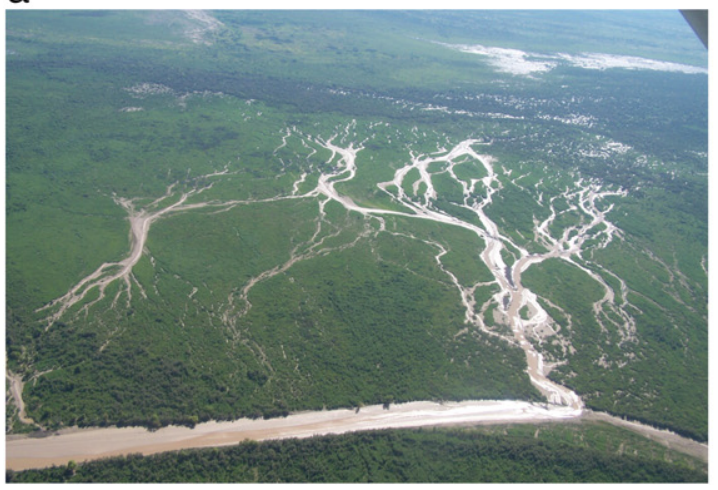

b

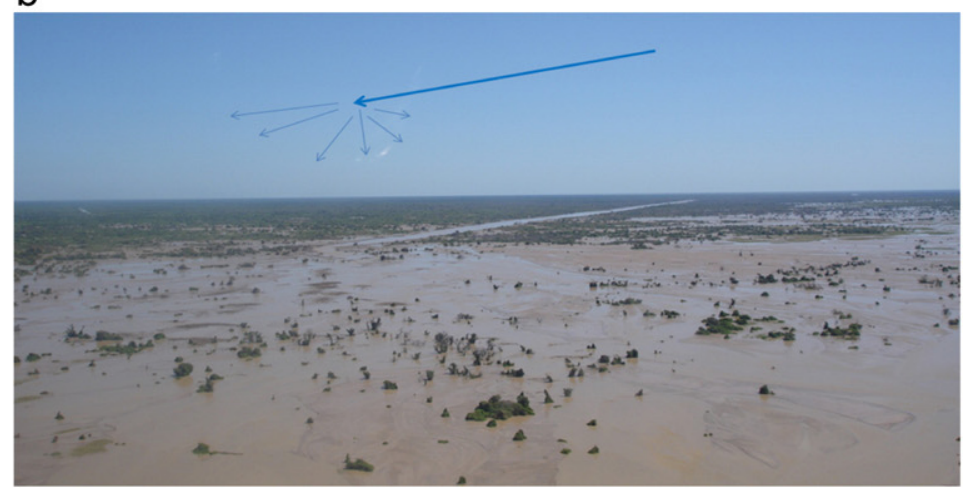

Fig. 8. Spilling at the jam in low (a) and high flow (b). Flow from left to right (a) and from background to foreground (b). The river is straight as explained in Section 4. 
a

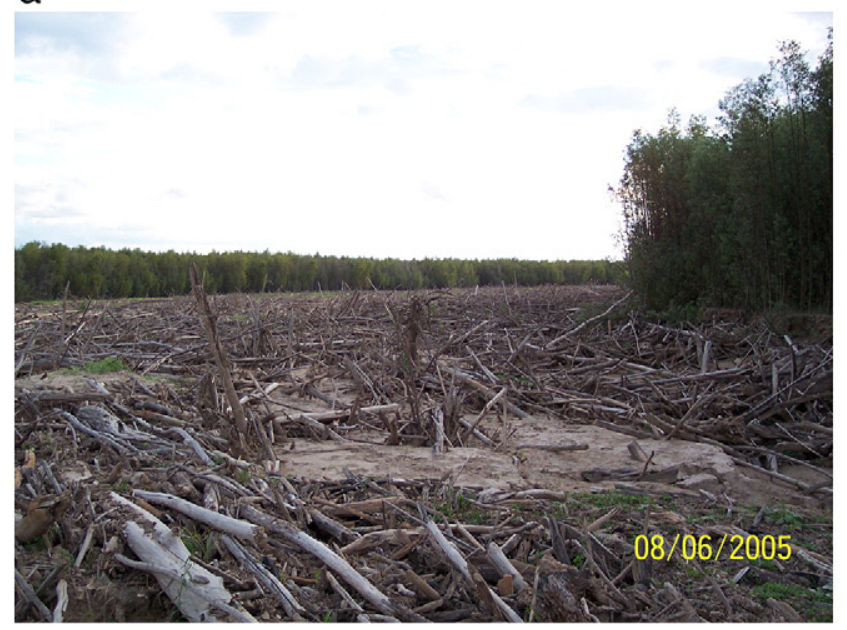

b

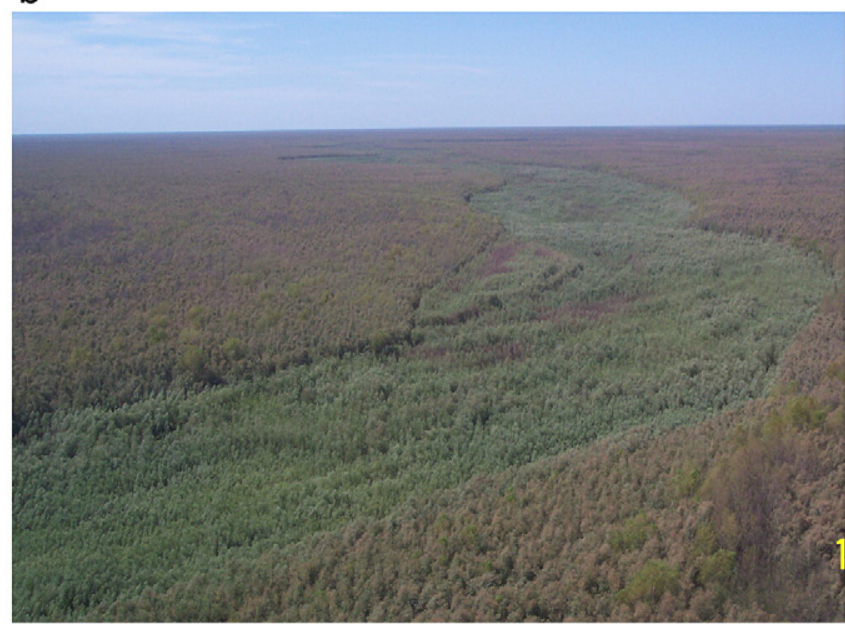

Fig. 9. View of the log jam from the ground (a). A channel colonized by vegetation one year after been abandoned (b).

First of all, a serious concern exists about avulsion. Each country fears that the Pilcomayo River will shift to the neighbor's territory in case of avulsion, therefore, losing its access to water and fish. The fan crest stands mostly in Paraguay nowadays with the Argentine land being lower (see Fig. 4). Differences of elevation between the two sides reach several meters. According to the theoretical building of an alluvial fan, the closer the channel to the sub-fan apex the likelier the avulsion is. With this idea in mind, it is understandable that the search for sub-apex within the mega alluvial fan is widespread in reports, but secondly this point transfers the "theoretical" fear of avulsion to the more objective fear of channel retreating. Both countries have witnessed spellbound the dramatic receding of the channel in the 20th century (Hopwood, 2003). At the beginning of the century the river kept its channel functional as far downstream as about $400 \mathrm{~km}$ from Asunción, where a large shallow marsh existed at that time. In the period 1947-76 the length of channel clogged was $150 \mathrm{~km}$, at a particular rate of $12 \mathrm{~km} /$ year in 1968-76 and a maximum of $22 \mathrm{~km}$ in 1976. Every retreat happened in the flood season - the loss was more or less severe depending on the magnitude of the floods that year, as will be discussed below. Meanwhile, in 1967, the gauging station 3 (Fig. 1) was overtaken and lost. Simply, the structure was going to stand forever over the dry filled trace of a forgotten river. The regions left by the moving collapse were standing relatively high in the fan and becoming more arid. In the period 1975-1990 another $150 \mathrm{~km}$, with a maximum of $45 \mathrm{~km}$ in 1984, were clogged (Fig. 10a). At that point the process was out of control and accelerating.

The threat of losing the river urged the two countries to an agreement in 1991. They decided to dig a pair of equal straight canals (Fig. 10b), with the shared hope of a fair water distribution as well. So far since then, the two canals have not worked simultaneously for long, but when one has succeeded the other has failed, which seems to prove an intrinsic instability. Failure of a canal means it is completely silted (clogged) after only one or two flooding seasons. Success means to keep water flowing, but with large maintenance costs every year. This maintenance consists of removing much sediment and wooden debris from the canals and the jam and trying to maintain the gradient, sometimes by discharging in lower areas. The receding of the Pilcomayo, or rather the receding of the straight surviving canal out of it, has been stopped so far, thanks to this work of maintenance. On the other hand, the fair water distribution has proven impossible and the river flows largely in one country now - the luckiest regarding alluvial fan relief and/or the most diligent in canal work. Obviously, these last two drawbacks may contribute to a

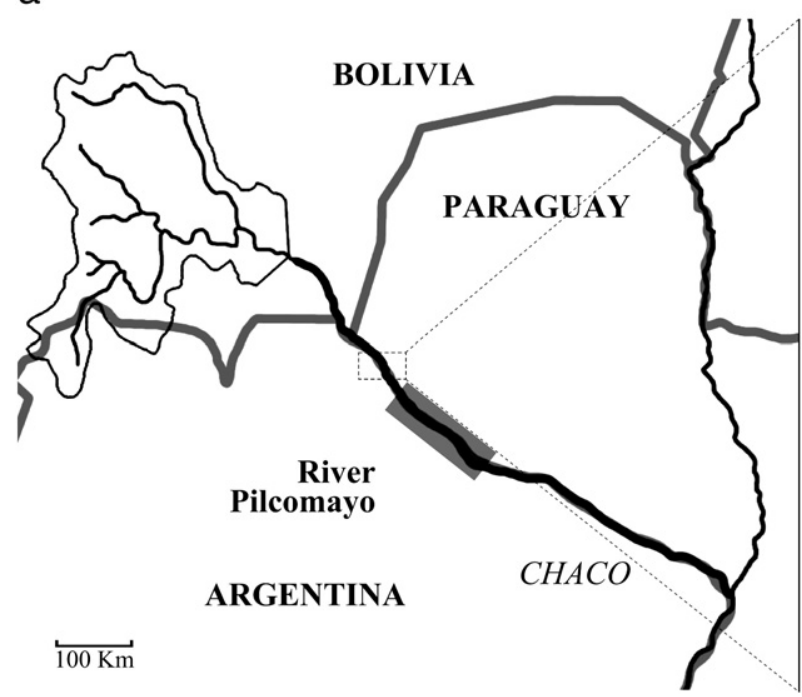

b

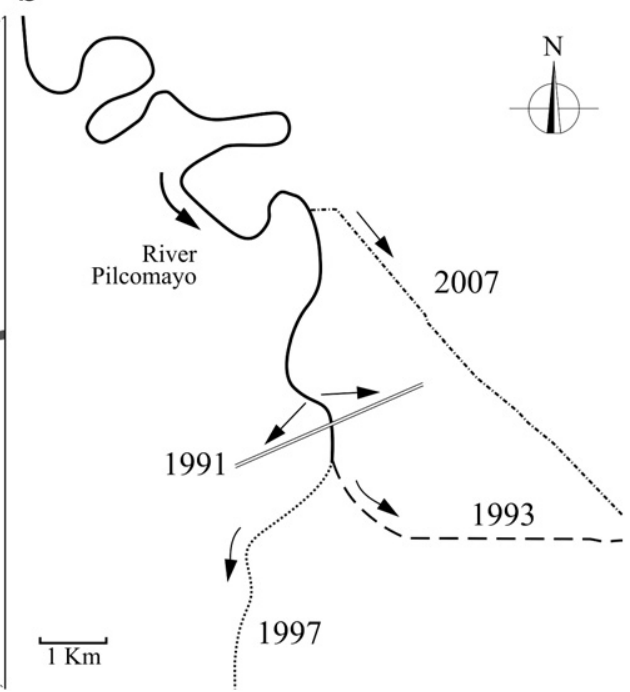

Fig. 10. (a) Channel length lost in 1976-90 (in bold line). (b) Canals dug by the two countries close to the point of collapse with the dates of construction. 
a mutual distrust. After failure, new canals have been designed by the countries ignoring the original agreement (Fig. 10b).

The response of these canals was an opportunity for observations regarding morphodynamics in case of a large wash load, such as shown in the photographs in Fig. 11. In November 2005, before the rainy season started, the straight canal to the right was about to be finished (a). The existing channel was quite sinuous. In the high flow of February 2006 (b) flow occurred in both branches although some deposits seemed to emerge in the left branch. In March 2006, during the falling limb of the hydrograph (c), the old channel was silted and the diversion to the right had captured the flow of the river. The fate of the old channel is to be quickly colonized by vegetation (see Fig. 9b). Therefore, one single flooding season was enough for one canal to capture the river in this case.

An explanation, based upon two principles, can account for these observations and so reinforce the idea of the intrinsic instability of splitting the river in two: $i$ ) flow in the canals is always subcritical (gradients are $0.02-0.03 \%$ ) and so, controlled by the downstream water level, and ii) in a branched system, fine suspended sediment is distributed at the same ratio as water. "Whoever takes a share of

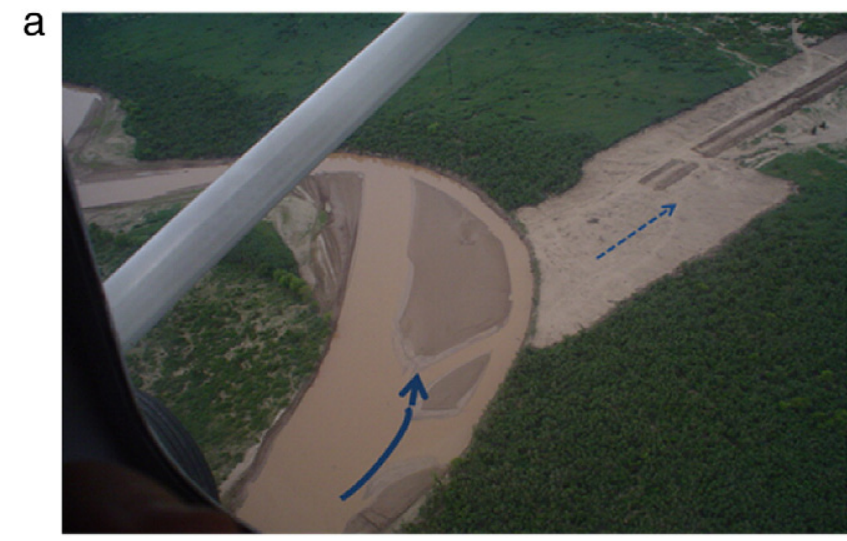

b

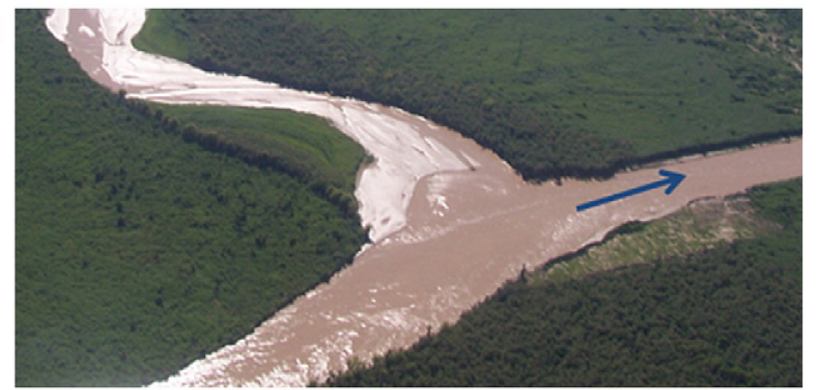

C

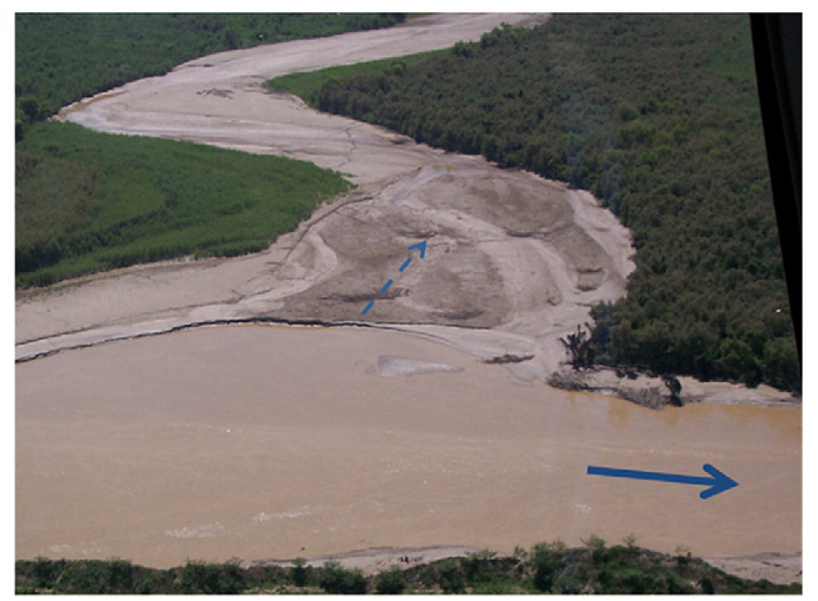

Fig. 11. Capture of the river by a canal in three pictures: November 2005 (a), February 2006 (b) and March 2006 (c). water, takes the same share of sediment as well" is a saying often heard and read. Following $i$ ) the downstream levels determine the discharge in the two canals. For example, backwater in one canal but drawdown in the other will unbalance a two-branch system in favor of a higher discharge in the second. Therefore, the first gets less water which flows more slowly. This promotes silting that in turn promotes more intense backwater, so that the unbalance intensifies.

\section{Discussion and perspectives}

The Pilcomayo is a tributary featuring an annual 3-month "pulse" of water and sediment that cannot reach its main river (the Paraguay). Whereas water spills over the plains, feeds the marshes and contributes to the groundwater so that it is finally drained far downstream as clear water, sediment has no other choice except to raise the land of the plains and fill the river channel itself, contributing altogether to the river channel instability in the alluvial fan. The river essentially reaches a local base level as it crosses the Chaco Plains, so that it spreads across the floodplain and fan complex.

The evolution of the Pilcomayo channel, turning from a braided to a meandering pattern in the flow direction, was to be expected, because an expectable reduction occurred in gradient $s$, though very severe in this case - from $0.12 \%$ to $0.03 \%$, i.e. four fold - accompanied by an unusual reduction in flow $\mathrm{Q}$ already explained in Section 2 . Both factors contribute to the evolution towards a meandering pattern according to the product of variables $s \cdot Q^{0.44}$ used as determinant of channel pattern.

Suspended sediment transport was measured at stations 2 and 3, $200 \mathrm{~km}$ apart, in the period 1964-1967 (four years), before the latter was caught by the river collapse. The mean monthly runoff $Q$ and sediment load Qs at stations 3 and 2 are compared in Fig. 12a and b. Q3 was well correlated with Q2, whereas Qs3 not so well with Qs2, as could be expected after the non-linearity and hysteresis of the Qs-Q relationship (see Fig. 3). Nevertheless, for more information the plot of Qs versus $Q$ for the four years of data in the two stations 2 and 3 is also given in Fig. 13 (the data are the same of Fig. 12, b but combined differently).

Overall $\mathrm{Q} 3=0.82 \cdot \mathrm{Q} 2$ and $\mathrm{Qs3}=0.64 \cdot \mathrm{Qs} 2$, i.e. less water as we already knew, but also less sediment crossing the downstream station than crossing the upstream one - besides, consequently sediment concentration $\mathrm{Cs}=\mathrm{Qs} / \mathrm{Q}$ decreases downstream, as well. The balance between sediment getting in and going out of the reach bounded by stations 2 and 3, with no tributaries in between, gives a net aggradation (siltation) within the reach, amounting to $0.36(=1-0.64)$ of the total load upstream. This applies to any season, high or low flow, because most data plot below the 1 to 1 ratio line of Fig. 12b. The region prone to siltation, however, differs whether the capacity of the channel close to collapse (assumed $200 \mathrm{~m}^{3} / \mathrm{s}$ ) is exceeded or not. In the first case, in 9 months (see Fig. 13) 0.66 of the total load is carried. It is thought that this load mostly settles in the floodplains after spilling, which contributes to land building. The load carried throughout the remaining 39 months with no spilling ( 0.34 of the total) must settle in the channel. The product 0.36 (unbalance) $\times 0.34$ (settlement inside the channel) $=0.12$ is an estimate of the fraction of the total load upstream that ends up filling the channel, or part of it, out of the $200 \mathrm{~km}$-long reach between stations 2 and 3 .

Wash load is the main fraction of the suspended load (some $89 \%$ ). It is made of particles smaller than $62 \mu \mathrm{m}$, produced and controlled by soil erosion in the basin (according to other reports, a significant contribution comes from mass movements). In the rainy season, a large wash load coming from the basin explains that the concentration Cs of this size in the suspended load is quite sensitive to $Q$ (power 0.82 in the $\mathrm{Cs}-\mathrm{Q}$ fitting). It also explains a mean particle size a little finer $(4 \mu \mathrm{m})$ than in the dry season $(6 \mu \mathrm{m})$. The power 0.29 in the Cs-Q fitting for particles larger than $62 \mu \mathrm{m}$ in the suspended load suggests 

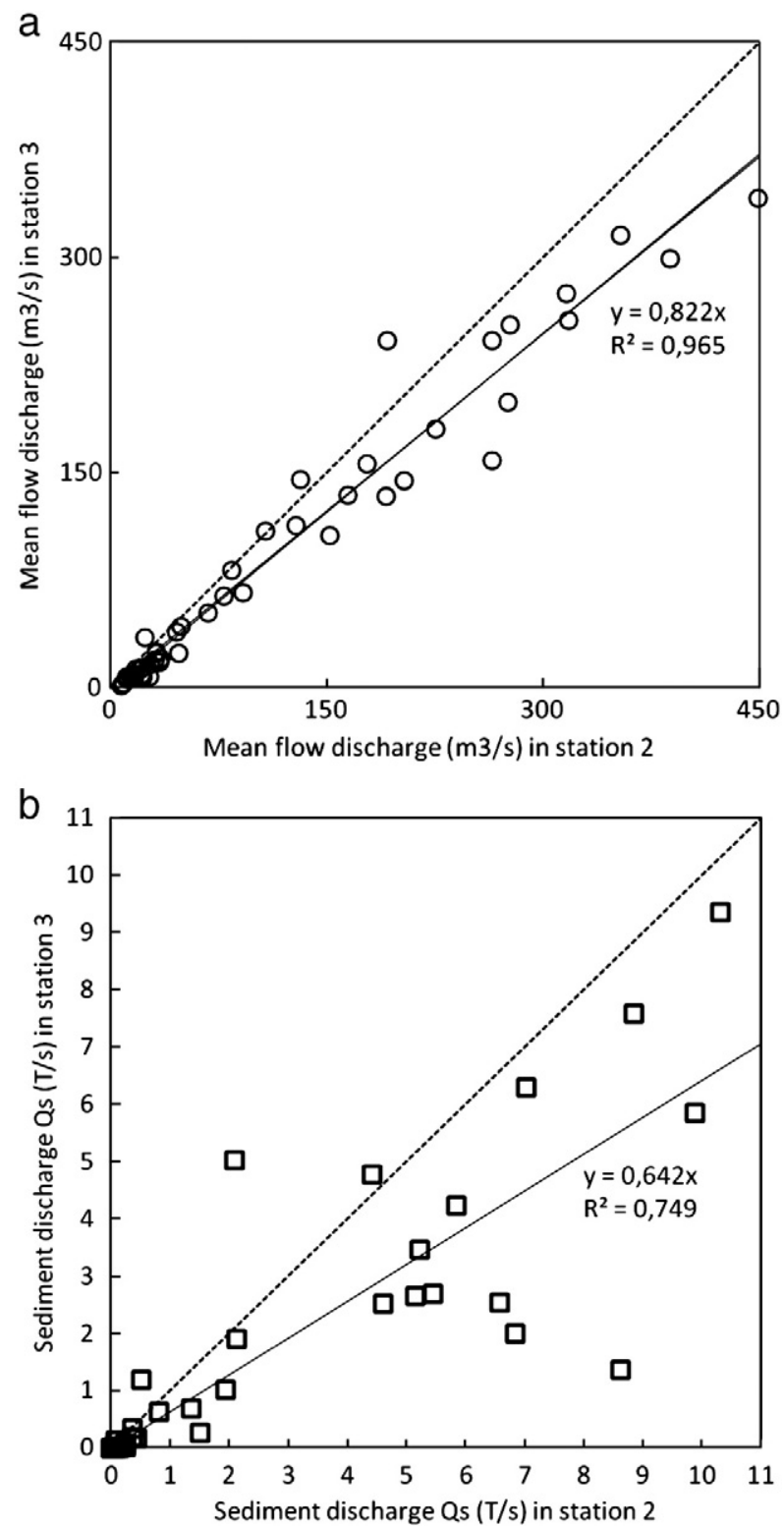

Fig. 12. a. Flow discharges expressed in monthly averages, at gauging stations 2 (upstream) in abscissa and 3 (downstream) in ordinate in the four years 1964-67. b. Suspended sediment discharges in monthly averages, at gauging stations 2 (upstream) in abscissa and 3 (downstream) in ordinate in the four years 1964-67.

a shift in control-channel control not basin control anymore. More importantly, the fall velocity of wash load particles, with size around $5 \mu \mathrm{m}$, is $\omega \approx 0.02 \mathrm{~mm} / \mathrm{s}$. The bankfull discharge in the $0.03 \%$-slope, 3 m-deep river channel would develop a bed shear stress of $\approx 9 \mathrm{~Pa}$, i.e. a shear velocity of $\approx 0.09 \mathrm{~m} / \mathrm{s}$, which is much higher than the fall velocity. This computation supports the assumption that wash load does not settle in the channel in the flood season, but across the floodplains, yet in the backwater flow, next to the log jam, the energy slope may decrease well below $0.03 \%$ so that some wash load may settle inside the channel. Curiously enough, the remaining $11 \%$ of the fine sand in suspension (i.e. the part of bed material load going into suspension) is a figure very similar to the estimate of the previous paragraph.

Furthermore, Table 2 compares the annual sediment load with the channel collapse location retreat. Among the nine years of data on retreat that are accurate enough, the year 1984 is outstanding because the load is double the average and the retreat four-fold the average. Fitting a straight line to these few data in Fig. 14, the correlation is

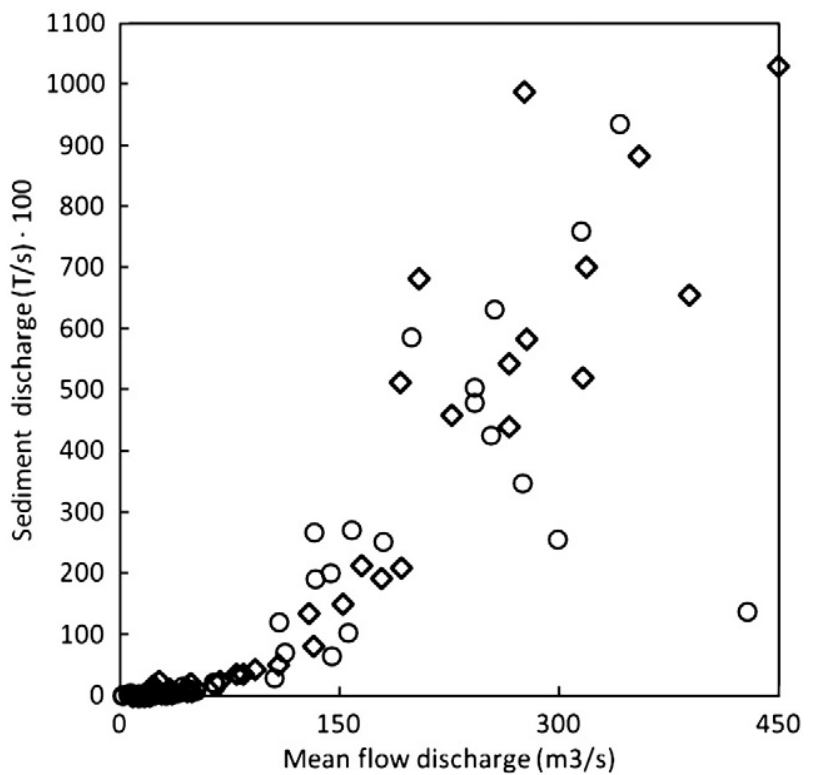

Fig. 13. Sediment discharge $(\mathrm{t} / \mathrm{s} \times 10)$ versus flow discharge $\left(\mathrm{m}^{3} / \mathrm{s}\right)$ for station 2 (diamonds) and 3 (circles) in the four years 1964-67.

rather weak $\left(R^{2}=0.62\right)$, but its slope means an average retreat of $11.6 \mathrm{~km}$ per each $100 \cdot 10^{6} \mathrm{t}$. Assuming again the size of the channel close to collapse as $150 \mathrm{~m}$-wide $\times 3 \mathrm{~m}$-deep and a specific weight of $2 \mathrm{t} / \mathrm{m}^{3}$, this length of retreat means that the channel takes to fill itself a share of $10.3 \%$ of the total load. This figure is very similar to the estimate of the previous two paragraphs. In summary, some $10-12 \%$ comes out as the fraction of the total load which is not wash load (after grain size) and, also, as the fraction of the suspended load settled within the channel (after a sediment balance and from the retreating channel geometry, as well).

The discussion of this section supports the conclusion of a causeand-effect process starting in the sediment production in the basin (wash load) and ending in the retreat of the point of collapse. Thomas J. Maddock, Jr., winner of the Kirk Bryan Award together with Luna B. Leopold in 1958, reported in 1978 that no reason exists to think that either the silting of the Pilcomayo or the filling of the channel was going to stop. Moreover, he wrote, since the Chaco exists in its present shape, the Pilcomayo River must have conveyed water and sediment to the Paraguay sometime in the past. What history says about this supports that the channel retreating in the 20th century has been an exceptional phenomenon. It seems that neither a major avulsion nor a loss of channel length occurred for centuries before 1900. The records of sailing expeditions dating back to 1546, 1721, $1741,1785,1844$, and 1863 and many more in the period 18701906 convey the impression of a continuity of water but a lack of depth for sailing, because of a "broken" river landscape made of large shallow marshes, channel branching and small waterfalls, too. In 1906 the large marsh located $400 \mathrm{~km}$ from Asunción was sailed successfully to find the Pilcomayo River some $100 \mathrm{~km}$ upstream. Then, the 20th century witnessed the silting of these marshes, the raising of its base level and, consequently, the receding of the river.

Table 2

\begin{tabular}{llllllllll}
\hline Year & 1975 & 1976 & 1984 & 1985 & 1986 & 1987 & 1988 & 1989 & 1990 \\
\hline $\begin{array}{c}\text { Volume } \\
\left(\text { tons } \cdot 10^{6}\right)\end{array}$ & 144 & 75.5 & 288 & 151 & 229 & 154 & 151 & 80 & 67 \\
$\begin{array}{c}\text { Length } \\
(\mathrm{km})\end{array}$ & 14 & 22 & 45 & 13 & 21 & 10.5 & 14.5 & 6.5 & 3.5 \\
& & & & & & & & &
\end{tabular}

Annual volume of suspended sediment load (in million tons) compared with the length of the channel lost (the retreat of the point of collapse, in $\mathrm{km}$ ). Data plotted in Fig. 14. 


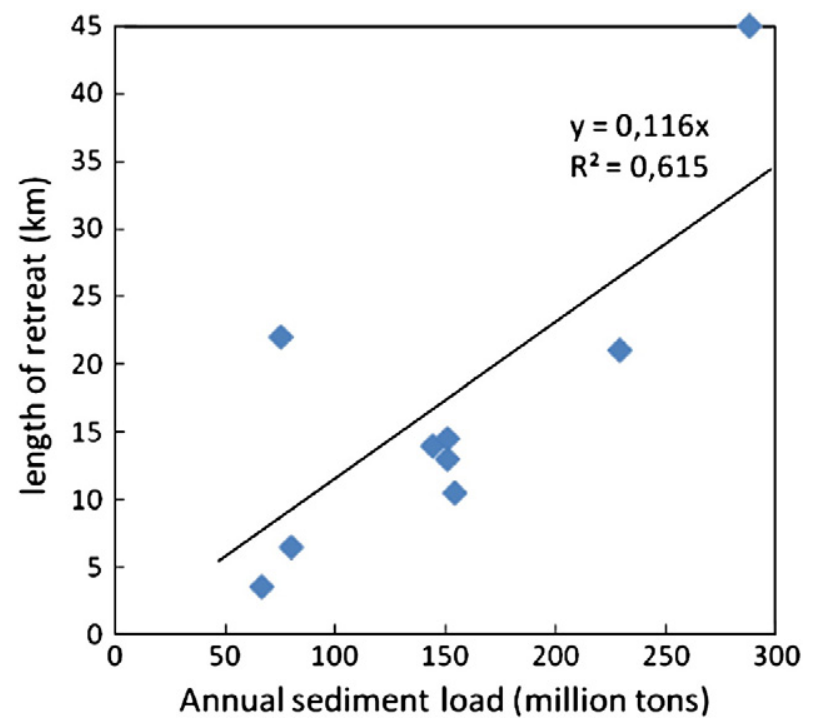

Fig. 14. Correlation between the length of retreat and the total suspended sediment load. Data from Table 2.

This point, together with the previous cause-and-effect conclusion, calls for an increase of sediment yield in the Andes in the 20th century.

The discontinuity in the Pilcomayo is a sediment-driven collapse, not a flow-driven collapse. The loss of flow moving down the megafan, as well as subtle changes in gradient, bank height, infiltration and other variables, however, may account secondarily for some portion of the collapse. The acceleration of the collapse point retreat as it moves up the fan needs an explanation that can spring from these flow variables.

The migratory fish Sábalo goes upstream to spawn in the upper part of the lowland river (Smolders et al., 2002). It seems that the marshes are an important habitat for them. They take advantage of the period from April to June for the annual migration, avoiding the previous floods, which they could not overcome, and the next dry period when channel and marshes become disconnected. In spite of the loss of river length and the receding of the channel, this species still manages to find the "active" channel for its migration, however catches of Sábalo are declining in the recent years. Whether the increasing fluvial discontinuity because of the channel receding is responsible of this decline is an open question.

The period for the Sábalo migration is a reminder that the biotic system is very sensitive to any change in the hydrological regime. The channel width, which is in balance with the Palo Bobo extending to the channel banks, depends on the discharge regime as well. Special care for the soils in the upland basin of Bolivia would be beneficial for the Pilcomayo not to yield such a huge wash load. It would help the two lowland countries in the dramatic (yet hopeless in the long run) fight against sedimentation, but a sudden cut in sediment would bring large changes in the river morphology and environment, harmful to the life in the river and to the means of living of the human population. Damming the river in the uplands, as often suggested during the European Union contract, would cause harmful changes in the hydrological and sedimentological regime.

The case-study of the Pilcomayo River should call the attention to the connection between the sediment yield from the basin, the sediment load in the river, the building of the alluvial fan and, finally, the possibility of a sediment-driven collapse of the channel. The geomorphology of other rivers on the eastern slopes of the Andes is quite similar. Some smaller ones show the same collapse, like the Parapetí to the North. Others, like the Bermejo to the South, are similar in size but do not show any collapse. The reasons whether the Pilcomayo is unique or not and the role of scale in the comparison between the Parapetí and Pilcomayo are well worth a future research.

\section{Acknowledgments}

Thanks to Mario Gamarra, Aurélie Malbrunot, Isabel Aguilar, Juan H. Hopwood, Sergi Capapé, Patricia Jaime and Mario Amsler.

\section{References}

Guyot, J.L., Calle, H., Cortés, J., Pereira, M., 1990. Transport of suspended sediment and dissolved material from the Andes to the Plata by the Bolivian tributaries of the river Paraguay (Pilcomayo and Bermejo). Hydrological Sciences Journal 35, 653-665.

Hopwood, H.J., 2003. The Continuing Blockage of the Pilcomayo River Channel. 1st Regional Symposium on River Hydraulics RIOS (in Spanish), Buenos Aires.

Horton, B.K., DeCelles, P.G., 2001. Modern and ancient fluvial megafans in the foreland basin system of the central Andes, southern Bolivia: implications for drainage network evolution in fold-thrust belts. Basin Research 43-63.

Iriondo, M.H., 1993. Geomorphology and late Quaternary of the Chaco (South America). Geomorphology 7, 289-303.

Orfeo, O., 1999. Sedimentological characteristics of small rivers with loessic headwaters in the Chaco, South America. Quaternary International 62, 69-74.

Smolders, A.J.P. Guerrero, M.A. Van der Velde, G., Roelofs, J.G.M. 2002. Dynamics of discharge, sediment transport, heavy metal pollution and Sábalo (Prochilodus lineatus) catches in the Lower Pilcomayo River (Bolivia). River Research and Applications 18, 415-427.

Vollmers, H.J., Palenque, G., 1983. Sediment Measurements in the Pilcomayo River. 2nd Intl. Symp. on River Sedimentation, Nanjing, 1050, p. 1070. 